\title{
O ARBÍTRIO DOS JUÍZES COMO EXERCÍCIO DA PRUDÊNCIA NOS PROCESSOS CRIMINAIS DO VICE-REINADO DO RIO DA PRATA ${ }^{1}$
}

\section{JUDGES’ ARBITRARY DECISIONS AS AN EXERCISE OF PRUDENCE IN THE CRIMINAL PROCEEDINGS OF THE VICEROYALTY OF THE RÍO DE LA PLATA}

\author{
Rafael Ruiz \\ Universidade Federal de São Paulo (Unifesp) - (São Paulo, SP, Brasil)
}

Recebimento: 8 mar. 2017

Aceitação: 5 ago. 2017

\begin{abstract}
Como citar este artigo / How to cite this article (informe a data atual de acesso / inform the current date of access):
RUIZ, Rafael. O arbítrio dos juízes como exercício da prudência nos processos criminais do Vice-Reinado do Rio da Prata. Revista da Faculdade de Direito UFPR, Curitiba, PR, Brasil, v. 62, n. 2, p. 131 - 148, maio/ago. 2017. ISSN 2236-7284. Disponível em: <http://revistas.ufpr.br/direito/article/view/51115>. Acesso em: 28 ago. 2017. DOI: http://dx.doi.org/10.5380/rfdufpr.v62i2.51115.
\end{abstract}

\section{RESUMO}

Este artigo procurará mostrar como a administração da justiça na América espanhola estava fundamentada, como um elemento estruturante de todo o sistema jurídico, no exercício da prudência e do arbítrio dos juízes. A prudência, que era exigida do juiz na elaboração e na definição da sua sentença, era exercida por meio do seu bom arbítrio. Ao contrário do que se costuma pensar, esse arbítrio não era sinônimo de injustiça nem de "arbitrariedade". Era fruto de uma longa tradição jurídica que entendia a vida social e a prática da justiça como algo essencialmente incerto, e era precisamente por meio de um arbítrio judicial prudente que essa incerteza podia ser convertida em justiça. Os documentos analisados neste trabalho são processos criminais, de um total de cem processos manuscritos, entre os anos 1770 e 1800, do Arquivo Histórico da Província de Buenos Aires (AHPBA), da cidade de La Plata, especificamente casos de adultério e de relações ilícitas.

\section{PALAVRAS-CHAVE}

América colonial. Arbítrio. Prudência.

\begin{abstract}
This article attempts to show how the administration of justice in Spanish America was based on the exercise of the judges' prudence and arbitration as a structuring element of the whole legal system. Prudence, a prerequisite for the elaboration and definition of the judge's verdict, was exercised through his scope of good decision-making. Contrary to what is commonly thought, this practice was not synonymous for injustice or "arbitrariness". It was the result of a long legal tradition which understood social life and the settling of legal affairs as essentially uncertain, and it was precisely through prudent and arbitrary decision-making that this uncertainty could be converted into justice. The documents analyzed in this paper are criminal proceedings (out of a total 100 manuscript cases)
\end{abstract}

\footnotetext{
${ }^{1} \mathrm{O}$ autor agradece à Fundação de Amparo à Pesquisa do Estado de São Paulo (FAPESP) pelo auxílio concedido para a realização desta pesquisa.
} 
from the Historical Archive of the Province of Buenos Aires (AHPBA), in the city of La Plata, decided between the years 1770 and 1800 and referring specifically to adultery and illicit relations.

\section{KEYWORDS}

Colonial America. Arbitrary decisions. Prudence.

\section{INTRODUÇÃO}

A maior parte da historiografia que estuda os processos judiciais da América hispânica colonial concentra-se no campo da história da família, da história de gênero ou da história da sexualidade. Assim, por exemplo, há estudos muito interessantes de Antonio Fuentes Barragán (2015a, 2015b), María Selina Gutiérrez Aguilera (2015a, 2015b) e Silvia Mallo (1990, 2009), para citar alguns mais recentes, que partem das mesmas fontes que este artigo - os processos judiciais do Arquivo da Província de Buenos Aires -, mas não pretendem o mesmo foco, e sim fazer história da família e da sexualidade a partir das fontes judiciais. Também têm trabalhos muito importantes Viviane Kluger (2009) e Jaqueline Vassallo (2009), principalmente do ponto de vista metodológico para tratar com esse tipo de fonte.

Em uma análise mais jurídica e da história do direito cabe destacar, pela proximidade com a análise deste artigo, os trabalhos de Osvaldo Barreneche (1993) e Alejandro Aguero (2008, 2014). São estudos que adentram muito mais na história da justiça e do direito do que na história da sexualidade ou da família, utilizando o mesmo tipo de fontes (processos judiciais de violência doméstica) e que pretendem, de forma resumida, no caso de Barreneche, analisar o tratamento que a justiça dava a esse tipo de delitos, e, no caso de Aguero, contestar a tese dominante, há tempos estabelecida por Tomás y Valiente, que relaciona direito penal e absolutismo, e estabelecer que, a partir das fontes judiciais do Vice-Reinado do Rio da Prata, pode ser constatado um estilo que responde não propriamente a anomalias ou ignorância próprios da periferia, mas a formas de entender o direito e fazer a justiça que eram próprias da cultura jurídica da época.

O ponto de análise deste trabalho está baseado na tentativa de mostrar que em uma mesma categoria jurídica - arbítrio - cabiam sentenças opostas, mais ou menos flexíveis, mais ou menos rigoristas, mas que todas elas estavam inseridas no que era entendido como prudência e, portanto, eram igualmente justas. 


\section{ALGUMAS REFLEXÕES EM TORNO AO ARBÍTRIO NOS TRATADOS DOS SÉCULOS XVII e XVIII}

Como muitas vezes se tende a entender o termo "arbítrio" como sinônimo de “arbitrariedade”, parece-me necessário fazer algumas considerações sobre o tema no contexto do Vice-Reinado do Rio da Prata, a partir dos tratados jurídicos e morais da época.

A maioria dos tratados jurídicos era concorde em entender que a principal função do juiz estabelecer a justiça por meio de uma sentença justa - só poderia ser realizada por meio da prudência. Não se tratava de agir a favor ou contra a lei, mas se tratava, sim, de saber interpretá-la.

Nesse sentido, apenas para citar alguns juristas de renome, Carrasco del Saz, que morreu no Panamá em 1625, onde foi ouvidor da real audiência, tendo sido anteriormente reitor da Universidade de São Marcos, em Lima, publicou um tratado sobre a interpretação das leis de Recopilação de Castela (1620), no qual explicava que havia duas formas de interpretação, a geral e a necessária, e que para os casos concretos que estivessem sendo julgados era tarefa do juiz interpretar adequadamente a lei tendo em conta, precisamente, o caso a ser julgado (CARRASCO DEL SAZ, 1620, p. 86).

Antes dele, outro jurista consagrado, Jerônimo Castillo de Bobadilla (1546-1605), corregedor nas cidades de Sória e Guadalajara e fiscal da chancelaria de Valladolid, e cuja obra teve uma imensa penetração em toda a doutrina jurídica dos séculos XVII e XVIII, afirmava que, tendo em conta que todas as coisas do mundo são mutáveis, não seria conveniente que a lei fosse inflexível e igual para todos e que, por isso, a lei e o direito eram de cera, porque mudavam as suas formas como Proteu (CASTILLO DE BOBADILLA, 1608, p. 471).

E já em pleno século XVIII, Guardiola y Sáez, autor de um tratado sobre o corregedor perfeito, exigia dos juízes, dentre as muitas virtudes morais elencadas no seu capítulo III, que fossem humildes, amantes da justiça, retos, firmes, fortes, leais, sem cobiça e, principalmente, sábios, prudentes e tementes a Deus (GUARDIOLA Y SAEZ, 1785, p. 129-131). Os juízes deveriam ter esse enorme número de virtudes e qualidades porque, como afirma o historiador argentino Tau Anzoátegui, estava-se literalmente nas mãos do arbítrio do juiz: “o arbítrio delegava ao juiz ou ao ministro a faculdade de decidir sobre uma situação determinada de acordo com a apreciação que realizasse das circunstâncias, das coisas e das pessoas” (TAU ANZOÁTEGUI, 1992, p. 534).

É claro que se as coisas eram assim, não se falava, então, em certeza jurídica, muito pelo contrário. Entendia-se que o campo jurídico estava perpassado pela incerteza e que, de acordo com a natureza das coisas e dos homens, o máximo a que se poderia aspirar era uma certeza moral. Diante de um universo enorme de opiniões e interpretações de uma mesma lei, a questão que se colocava, 
para os juízes, era a de qual delas seguir. Daí que, por outro lado, os tratados de moral estivessem preocupados em resolver precisamente esse grau de certeza ou de incerteza moral.

O termo moral, nesse contexto, não deve ser entendido como aquele que diz respeito a convenções sociais ou religiosas, mas como aquele relacionado à responsabilidade pessoal diante do juízo de Deus. Daí que os tratados de moral tratavam primeiro sobre a consciência e, depois, elaboravam reflexões e argumentações morais sobre todas as possíveis circunstâncias da vida, muitas vezes de forma prolixa e casuística.

São inumeráveis os tratados que foram escritos ao longo desses dois séculos, mas todos eles, de acordo com um consenso geral dos historiadores, preocuparam-se em discutir até que ponto, diante de uma decisão ou de um ato concreto a ser realizado, se poderia ter certeza sobre a opinião a ser seguida.

Nesse sentido, a Companhia de Jesus teve um papel de destaque na construção de respostas morais diante das inúmeras questões incertas que iam surgindo como consequência, entre outros motivos, da descoberta da América e da sua colonização. No começo do século XVII, o jesuíta Juan Azor (1536-1603) publicou em Roma as suas Instituições morais² (AZOR, 1600), procurando "abarcar todo o conjunto da matéria moral a partir do ponto de vista da consciência que realiza a separação entre o bem e o mal” (PINCKAERS, 2000, p. 315).

Recentemente, Robert A. Maryks, numa interessante obra sobre a influência de Cícero nos estudos humanistas da Companhia de Jesus, aponta para a mudança que se produziu a partir deste momento em todo o mundo católico, sob o ponto de vista da moral. Para Maryks, a geração de jesuítas do começo do século XVII teve a ousadia de romper com a tradição ética medieval e dar uma resposta já moderna à incerteza moral, introduzindo no debate dos juristas e dos moralistas "um alto grau de subjetividade, de responsabilidade e de interioridade” (MARYKS, 2008, p. 117). Esse ponto de vista moderno diversificava as opiniões, multiplicava as soluções e estabelecia limites muito mais largos, deixando de lado a ideia de uma solução ou resposta única, melhor e perfeita, típica da ética medieval.

Em termos concretos, era já uma opinião comum e corrente, no século XVII, que para agir prudentemente não era mais necessário escolher o melhor ou o mais perfeito (MARYKS, 2008, p. 118). Bastava que a opinião ou a conduta que fosse seguida fosse apenas razoável e estivesse apoiada na autoridade de um bom autor, mas não era obrigatória seguir nem a mais razoável, nem a mais segura, nem a que estivesse apoiada num maior número de autores. Os moralistas - a grande maioria

\footnotetext{
${ }^{2} \mathrm{O}$ título era bem significativo do que se pretendia: Institutionum moralium, in quibus universae questiones ad conscientiam recte aut prave factorum pertinentes breviter tractatum (Sobre as instituições morais, nas quais são tratadas todas as questões pertinentes a uma consciência reta ou errada) (Tradução nossa).
} 
nos séculos XVII e XVIII - que seguiam essa forma de pensar foram chamados opinatores e, mais para o fim do XVIII, quando a crítica se tornou mais forte, probabilistas.

O que verdadeiramente foi revolucionário nesse contexto foi a afirmação e a prática de que, diante de uma incerteza moral - que, como vimos, poderia ser tudo o que fosse jurídico - era lícito seguir, de acordo com o juízo subjetivo em boa e reta consciência da pessoa, qualquer opinião provável, mesmo que fosse ou parecesse ser menos provável que as outras, sem medo de cometer nenhum pecado (MARYKS, 2008, p. 116).

A questão, também a questão jurídica - porque em todos esses tratados se falava da função do juiz, do seu papel na administração da justiça, e das sentenças - era que quem agia seguindo a opinião provável agia sempre prudentemente. E era precisamente nesse ponto que se entroncavam, para o caso dos juízes e da administração da justiça, o moral e o jurídico, a prudência e o arbítrio.

\section{A QUESTÃo DO ARBÍTRIO E DA PRUDÊNCIA NOS PROCESSOS CRIMINAIS}

Os casos apresentados correram na justiça entre 1788 e 1791 e estavam tipificados como “atentados ao matrimônio”, sendo “conceptuados” - era a expressão jurídica que se utilizava - como adultério, amancebamento ou amizade (relação) ilícita. São termos utilizados indistintamente nos processos, tendo como elemento comum a todos eles o fato de que, na relação sexual mantida pelo homem e a mulher, um dos dois estava casado e, portanto, impedido, legal e moralmente, de manter esse tipo de relação.

Analisando-se os processos percebe-se como os juízes tinham efetivamente o poder de julgar conforme seu arbítrio, hoje diríamos conforme a sua convicção, o que não significava que julgassem arbitrariamente, mas conforme ao alegado e provado, porém, de acordo com o que consideravam mais ou menos justo, variando-se a decisão de juiz para juiz. E, portanto, havia uma pluralidade de decisões. Ou seja, diante de um mesmo “tipo penal” - o termo utilizado era “concepto” (por exemplo, estupro, adultério, maus tratos, relações ilícitas...) - não havia uma sentença igual à outra, nem uma pena similar em todos os casos do tipo; pelo contrário, verifica-se que em situações semelhantes e casos iguais cada juiz julgava e sentenciava diferentemente. E, nesse sentido, nem caberiam, nem se poderia propriamente falar, em "precedentes”. Cada caso era mesmo um caso.

O motivo da escolha de processos muito próximos cronologicamente explica-se porque considero que é mais fácil perceber como, num mesmo período, podem ser encontradas sentenças distintas, baseadas num mesmo princípio, não apenas de juízes diferentes, mas inclusive do mesmo juiz. 
Para facilitar a compreensão, vou concentrar-me em três processos de adultério e dois de relações ilícitas, e procurarei mostrar como o arbítrio era exercido pelos juízes ao longo de todo o processo, com resultados diferentes. Para isso, escolhi dois pontos de vista: o do devido processo legal e o da apreciação das provas.

\section{O ARBÍTRIO NO DEVIDO PROCESSO LEGAL}

A normativa e a prática processual no caso do delito de adultério era que o processo corresse de forma "reservada”, ou seja, sem a publicidade própria do processo comum, a não ser que o marido (a mulher não tinha direito de ação) tivesse iniciado a ação e, nesse caso, a reserva já não era necessária. O motivo mais importante que normalmente era indicado era o desejo de preservar a união matrimonial.

O primeiro caso foi iniciado de ofício pelo alcalde ${ }^{3}$ ordinário de $2^{\circ}$ voto, dom Miguel Saenz, aos seis de agosto de 1788 (ARCHIVO HISTÓRICO DE LA PROVINCIA DE BUENOS AIRES, 1788a), como consequência de uma denúncia anônima, que não era do marido.

O juiz dirigiu-se, de madrugada, à casa de uma mulher casada, Florência Azevedo, e encontrou-a com dois homens - o suposto amante, dom Francisco Cavenago, e um amigo deste, Antonio Carmona. Mandou prender os dois homens no cárcere público e que a mulher fosse recolhida à Casa de Exercícios.

O juiz formou, então, o sumário (a primeira das partes que compunham um processo criminal), ouvindo as confissões das partes envolvidas e as declarações de duas testemunhas - dois escravos negros, Antonio Villota e sua mulher Francisca Rubio -, e enviou os autos para o fiscal do crime, responsável por formular devidamente a acusação formal e solicitar a pena. O fiscal reconheceu que, de acordo com as testemunhas, "é manifesto um público e escandaloso amancebamento nestes sujeitos” (f. 12v). E, por isso, uma das primeiras medidas que tomou foi o de solicitar que o nome da mulher fosse riscado em todas as partes do processo (de fato, assim foi feito, menos em um, provavelmente por descuido, em que o escrivão deu notícia de uma diligência tomada em relação a Florência Azevedo, deixando seu nome sem riscar), "para cautelas dos inconvenientes que da manifestação pública do nome de qualquer mulher casada nestes casos possam sobrevir” (f. $12 \mathrm{v})$.

\footnotetext{
${ }^{3}$ Utilizo o termo alcalde, ao longo de todo o artigo, por corresponder ao original. Poderia ser traduzido por juiz.
} 
A seguir, apoiando-se na Lei $2^{a}$, tit. 19, lib. 8, de Castela, que determinava que processos criminais desse tipo só poderiam ser iniciados por requerimento e acusação expressa do marido coisa que não aconteceu -, pediu para que o processo fosse extinto e "arquivado secretamente [...] e que sejam advertidos para que evitem a má nota que já aparece” (f. 13r). O fiscal referia-se ao fato de que o procedimento judicial que já tinha sido iniciado com a sumária não deveria ter sido nem sequer começado, devendo seguir todo o processo de forma secreta e reservada para evitar, principalmente, não apenas o escândalo público, mas problemas e inconvenientes no casamento.

A sentença foi dada logo a seguir, determinando o alcalde Miguel Saenz que todos os três envolvidos fossem postos em liberdade e que fossem também advertidos a não reincidirem (f. 13v). Manteve-se, portanto, embora não de forma completa, a reserva e o segredo desse tipo de processo.

Na sentença da real audiência, aos 29 de agosto de 1788, não só se confirmou a do alcalde ordinário, como se acrescentou que "fosse riscado e apagado o nome da mulher que resulta cúmplice, arquivando-se secretamente a causa” (f. 17v).

O segundo caso, também acontecido em Buenos Aires, aos 16 de maio de 1789, começou, desde o início, por ofício do juiz (o mesmo juiz do anterior) e de forma reservada (não houve, por exemplo, a tomada de declarações das testemunhas), ao contrário do anterior (ARCHIVO HISTÓRICO DE LA PROVINCIA DE BUENOS AIRES, 1789b).

O processo iniciou-se com uma denúncia oferecida pelo fiscal protetor dos naturais, em nome do marido de Fructuosa Polibio, mulata e escrava do dono de uma pulpería, Juan Polibio, acusando o alcalde, Miguel Saenz, de ter procedido ilegalmente, com abuso de poder e sem formar o devido processo legal, porque, “com a desculpa do poder que exerce e sem motivos legais para tanto” (f. 1r), pretendia fazer embarcar a mulher do autor do processo num navio, com a condição de que fosse vendida em Santa Fé, Corrientes ou Córdoba, mas fora do território e da jurisdição de Buenos Aires. Até aqui o marido não sabia, nem saberá, a verdadeira causa e motivo que levaram o juiz a agir dessa forma. Ou seja, a acusação era apenas de “abuso de poder” por parte do juiz que, de forma ilegal, estava enviando a mulher do autor do processo para longe de Buenos Aires.

A seguir, com a rubrica de "Reservado" na parte superior, vem um longo texto, escrito primeiro pelo escrivão e, depois, pelo alcalde. O escrivão confirmava que Fructuosa Polibio era de nação estrangeira, escrava de Juan Polibio e que estava casada com o índio guarani, Josef Antonio Castro, e informava que o alcalde lhe comunicou que não tinha formado processo nenhum "porque lhe pareceu que assim o exigiam as circunstâncias que exporá à Vossa Alteza com toda individualidade” (f. 11r). E mais: explicava que o caso era "verdadeiramente particular”, tendo em conta a quantidade de atos criminosos que foram realizados “por parte do 'pulpero', vivendo num 
escandaloso amancebamento com Fructuosa, sua escrava” (f. 11v), seguindo-se oito folhas com a explicação dada pelo alcalde aos membros da Real Audiência.

Nesse informe reservado, o alcalde comunicava que fora ele próprio quem vendera a escrava para Juan Polibio, mas que, passado o tempo, ficou sabendo que "vivia prostituída com o citado 'pulpero”” (f. 11v) e que tentou corrigi-los, mas sem resultado, porque o que aconteceu foi que “deu mérito para sua maior prostituição” (f. 11v).

O dono da escrava, sentindo-se prejudicado, revendeu-a para um homem que trabalhava no Coliseo de Comedia, contudo, mais tarde, a mulher desse homem veio procurar o alcalde informando que fora uma compra fraudulenta, que, na verdade, Fructuosa continuava sendo explorada e obrigada a prostituir-se em benefício do pulpero, antigo dono (f. 12r). Diante dessa informação, o alcalde tomou medidas para que tanto o pulpero Juan Polibio quanto Fructuosa Polibio fossem presos, mas diante da pressão de várias pessoas da cidade, libertou Juan sob a condição de que vendesse a sua escrava fora dos limites da cidade, “com a justa ideia de evitar o amancebamento em que estavam obstinados”. A escrava continuou presa até que se verificasse essa nova venda (f. 12v).

Mais uma vez, Juan Polibio utilizou-se de meios fraudulentos, procurando um intermediário para efetuar a compra - no caso, uma mulher chamada Maria Melchora, a quem ele devia 500 pesos. Contudo, na hora de realizar a venda, Polibio negou-se a fazê-lo, e Melchora foi denunciá-lo, novamente, ao alcalde. Foi nessa altura que o alcalde decidiu fazer diligências para embarcar Fructuosa num navio que a levasse até Santa Fé, longe do pulpero. Foi também nessa altura que o marido de Fructuosa, Josef Antonio Castro, voltou para Buenos Aires, vindo do interior, onde se encontrava prestando serviços para seu amo, porque também era escravo. E, incitado por Polibio, que queria impedir que o alcalde enviasse Fructuosa para longe de seu poder, animou o marido dela para que processasse o alcalde, por abuso de poder.

O alcalde, Miguel Saenz, considerando que "não seria justo manifestar-lhe [ao marido] os motivos antecedentes da resolução tendo em conta e respeitando a honra do matrimônio, que foi o único motivo de não formar processo no assunto” (f. 13v), acabou por convencer Josef Antonio Castro de que poderia ir junto com sua mulher para as terras de Santa Fé ou Corrientes, de onde ambos eram originários, coisa que o índio guarani “aceitou sem violência” (f. 13v).

Depois de expostos todos os fatos, o alcalde, dirigindo-se diretamente à Audiência, expôs que não era de estranhar "que o marido suponha inocente à sua mulher, porque ignora tudo o acontecido” (f. 14r), ainda mais tendo-se em conta “a quantidade de tempo que a deixou abandonada e quando ao amo da sua mulher não lhe faltam manobras como as que teve para viver como prostituto com a sua escrava” (f. 14v). 
Por último, o alcalde ainda argumentou que se o que movia o fiscal do crime a processá-lo era a honra do matrimônio, “essa mesma honra foi a que moveu Vosso Alcalde para fazer o que fez porque não lhe pareceu justo processar o pulpero porque tornando-se ainda mais público o seu amancebamento acabasse prejudicando o matrimônio” (f. 14v). Disse ainda que concordava que poderia ter dado publicidade aos atos processuais, mas que considerou "mais justo tirar a ocasião próxima do delito da escrava com o seu amo por um meio tão suave e tão natural procurando com zelo que não se façam ofensas ao casamento nem a religião” (f. 15r).

O alcalde, portanto, sabia que o procedimento que utilizara ia além dos seus poderes legais; que, de fato, a acusação feita pelo fiscal em nome do marido podia ser considerada procedente: houve um abuso de poder, agiu além dos seus limites jurisdicionais e, mais, tomou a inciativa sem levar em conta que, de acordo com a lei, para esse tipo de crimes só o marido é que tinha a iniciativa. Contudo, o alcalde também considerava que essas medidas ilegais é que eram precisamente as medidas justas e adequadas para esse caso.

De acordo com a argumentação da sua defesa enviada à Real Audiência, parece manifesto que o entendimento que o próprio alcalde tinha sobre a sua função e sobre o que deveria ser considerado como justo estava perpassado por considerações morais e religiosas. A utilização do termo “ocasião próxima de delito” tinha uma conotação claramente canônica e religiosa. É a expressão que se utiliza na Igreja Católica para advertir os fiéis no sentido de que, para evitar o pecado e não cair em tentação, é necessário evitar a ocasião próxima de pecar. Há, portanto, no alcalde Saenz, nesse processo, uma atuação muito mais próxima da figura do sacerdote do que da do juiz.

O pleno da Real Audiência, cinco ouvidores, rubricou e escreveu na margem da primeira folha do informe reservado: "visto o informe com as suas considerações, declaram-se as operações do Alcalde ordinário regradas e prudentes [...] e arquive-se este expediente” (f. 11r).

O último caso também trata de um adultério, contudo o que mais chama a atenção neste processo é que tanto o alcalde, desde o começo da ação, quanto a Real Audiência, na fase final, mesmo com a oposição sistemática tanto do fiscal do crime quanto do advogado dos réus, não só dão publicidade à ação, mas determinam que sejam enviadas cartas requisitórias (três cartas) à procura do marido para que tome conhecimento dos fatos e acabe por reunir-se com a mulher. Foi também um processo longo, passando de 1788 para 1789, em que todos os funcionários envolvidos - alcalde, fiscal e advogados - foram substituídos no começo do ano de 1789.

O processo (ARCHIVO HISTÓRICO DE LA PROVINCIA DE BUENOS AIRES, 1788b) envolveu um homem de 40 anos, solteiro, capataz da tropa de milícias de dom Luis Surlin, Gerônimo Toro Caparrós, e uma mulher casada, Juana María Román, de não mais de 18 anos, conforme constava 
nos autos da sua confissão, mulher de Joaquín Báez, peão tropeiro, sob a acusação de que além de adúlteros, eram perjuros, já que tinham declarado, perante o alcalde de $2^{\circ}$ voto de Córdoba del Tucumán, dom Francisco Antonio Gonzalez, num inquérito preliminar realizado em sua jurisdição, que eram casados, obtendo assim permissão para que viajassem para Buenos Aires.

Pelas confissões dos réus, ficamos sabendo que o relacionamento de ambos teria começado apenas duas semanas antes dos fatos narrados. Toro desconheceria que Juana María era casada e só teria ficado sabendo disso quando, pouco antes de ir com a tropa desde Córdoba e até Buenos Aires, a mulher o procurou e lhe pediu que a levasse junto com ele porque era casada e queria encontrar-se com seu marido, que havia dois anos se encontrava trabalhando na região de Buenos Aires.

Conforme o capataz disse ao juiz, tudo o que se passou e fez com Juana María foi “com o seu consentimento, sem que houvesse violência, interesse ou engano, sem nenhum outro motivo que o da complacência de ambos” (f. 8r). E a ré não negou esse fato; pelo contrário, confirmou-o, explicando que Gerônimo a requereu “com palavras brandas e suaves, ela, sendo frágil e estando ausente o seu marido, condescendeu e que viveram assim por duas semanas” (f. 10v).

Seguindo o procedimento dos outros dois casos, o regedor defensor geral de pobres, aos nove de setembro de 1788, em nome de ambos os réus, apresentou uma defesa baseada não apenas na lei, mas nos precedentes da própria Real Audiência.

Dizia o defensor que esse tipo de crime só poderia ser denunciado e iniciado processualmente pelo marido, e que se tinha procedido neste caso "em contra do prevenido pela Lei Régia de Castela que não permite que nenhum outro possa acusar este delito a não ser o próprio marido” (f. 14r), argumentando ainda que era “do conhecimento da Real Audiência desta Corte ter resolvido recentemente dois casos iguais, ordenando o primeiro a extinção do processo, pondo em liberdade os presos, e o segundo aprovou esta mesma providência nos termos expedidos pelo Tribunal” (f. 14r). O defensor finalizava sua argumentação recordando que, em casos como esses, devia ter-se em conta que o réu desconhecia a condição de casada da ré e "principalmente se deve atender à conservação do matrimônio e união dos consortes” (f. 14r).

No mesmo sentido e de forma ainda mais veemente e explícita manifestou-se o próprio fiscal do crime, licenciado Mantilla, que seria o encarregado de apresentar a acusação formal e o pedido da pena. Disse que, embora a prisão preventiva decretada “foi oportuna para evitar a ofensa de Deus” (f. 15r), a ausência de qualquer diligência teria sido “mais louvável” (f. 15r), e que se alguém deveria ter sido acusado deveria ser o marido. E, mais, que uma vez que o delito se tornou público e o marido não tomou nenhuma medida, "sua tácita condescendência e a sua ausência agem legalmente em favor da mulher e do réu” (f. 15r), razões pelas quais considerava que a ação deveria ser extinta, o capataz 
deveria ser liberado e a mulher colocada numa casa honrada, até que pudesse ser enviada de volta para a sua casa.

Como se pode ver, tanto o defensor quanto o fiscal solicitaram que o processo fosse encerrado, e não houve nem acusação nem pena solicitada. Contudo, o alcalde ordinário de $1^{\circ}$ voto de Buenos Aires, Manuel Warnes, ordenou que fosse enviada uma carta rogatória ao alcalde de Córdoba, para que efetuasse diligências para procurar Joaquín Báez, marido de Juana María e que deveria ser informado sobre o processo em andamento, mantendo-se os réus presos, à espera de que o marido fizesse a acusação formal.

Mesmo com a apelação feita pelo novo fiscal do caso à Real Audiência, dom Mariano Zabaleta (houve a mudança na passagem do ano), alegando que, num caso como esse, mesmo que houvesse presunção de delito, “não legitima os procedimentos de ofício, nem torna as disposições efetuadas conforme à regra” (f. 23v), expediu uma nova rogatória e, diante do novo apelo por parte do fiscal, informando que o marido de Juana não era encontrado e que, enquanto isso, os réus continuavam presos havia mais de um ano, expediu ainda uma terceira carta, solicitando que se procurasse Joaquín Báez que, finalmente, foi encontrado e deslocou-se até Buenos Aires, de onde retirou sua mulher, no dia 30 de janeiro de 1790, quando a sentença final já tinha sido dada, sem a acusação por parte do marido.

Como disse, parece-me que o que mais chama a atenção nesse último processo não é apenas a decisão de dar publicidade aos atos processuais quando, contrariamente à lei, o marido não foi o autor da acusação de adultério, mas a insistência por parte do juiz ordinário, Manuel Warnes, e dos ouvidores da Real Audiência, para que o marido fosse encontrado e tomasse conhecimento do processo. E mais, o arbítrio do juiz é de tal forma amplo que ele não apenas agiu de ofício abrindo o processo, mas tomou conta dele totalmente, desconsiderando o fato de que o próprio fiscal do crime, a pessoa legítima que deveria formalizar a acusação e solicitar a pena, havia pedido a extinção do processo por considerar que era, sim, uma ofensa a Deus, mas não um delito a ser condenado, por faltar o requisito prévio de acusação por parte do marido.

Como disse o historiador italiano Massimo Meccarelli, o arbítrio do juiz estava relacionado semanticamente a termos como "vontade”, “juízo”, “consciência” ou “discriminação”, expressões que deixam claro que o seu exercício, como espero ter mostrado, não estava determinado nem era possível de ser determinado a priori (MECCARELLI, 1998, p. 38). Mesmo assim, não significava, contudo, que fosse um exercício arbitrário. A lei geral sem o arbítrio do juiz não seria justa em muitos casos. O bem que se estava querendo proteger nos três casos estudados era a união do casamento, e não a Lei Recopilada de Castela. 


\section{O ARBÍTRIO NA APRECIAÇÃO DAS PROVAS}

A questão da apreciação das provas é uma das mais interessantes quando se está discutindo a função do arbítrio judicial. Como lembra o famoso processualista Michelle Taruffo (2014, p. 19), os “fatos” sobre os quais trata o litígio são uns fatos peculiares: “em geral, já ocorreram e, assim, pertencem ao passado. Em consequência, salvo alguns elementos de prova circunstancial, os fatos não podem ser percebidos pelo juiz: esses devem ser reconstruídos pelo julgador com base na prova disponível”. Nesse sentido, acrescenta ainda Taruffo (2014, p. 34), “pode-se afirmar que um fato é verdadeiro somente quando provado com base nos elementos de prova, e se prova unicamente quando sua verdade nesses se funda”.

A questão que se coloca, então, é como o juiz podia ter certeza de que uma prova, de fato, provava algo? Ou, então, podia o juiz dar mais valor a uma prova do que à outra? De acordo com o jurista italiano e historiador do direito, Antonio Padoa-Schioppa, foi no começo do XVI que surgiu um conceito jurídico-moral destinado a afirmar-se durante toda a Idade Moderna e Contemporânea: a ideia de “certeza moral” como fundamento necessário e suficiente para pronunciar um juízo relativo aos fatos humanos. E, junto com a ideia de certeza moral, surgiu a de "diferentes graus de probabilidade" que um determinado fato podia ter aos olhos do juiz para dar uma sentença justa (PADOA-SCHIOPPA, 2001, p. 154). E aqui, novamente, se dará o ponto de encontro entre o jurídico e o moral, entre a prova e o provável.

Serão então analisados dois processos em que não havia provas concludentes para a sentença. O primeiro é um caso de incesto entre dois irmãos e o segundo o de uma tentativa de estupro, por um conhecido da família, que frequentava a casa onde ocorreu o fato.

São casos, como se deixa claro no correr dos dois processos, em que a prova plena é muito difícil e que, portanto, só podem ser provados por indícios, conjeturas ou presunções. Em ambos, os juízes ordinários sentenciaram absolvendo os réus; contudo, a Real Audiência mostrou-se mais rígida no primeiro caso, condenando os irmãos a dois anos de reclusão, e, no segundo, mais flexível, confirmando a sentença absolutória. O significativo aqui, como disse, é que ambos estavam apoiados no conceito jurídico de “indício”. Num caso, entendeu-se de uma forma, e no outro, de outra.

No primeiro processo (ARCHIVO HISTÓRICO DE LA PROVINCIA DE BUENOS AIRES, 1790) os irmãos Francisco, de 31 anos, e Margarita Balcázar, de aproximadamente 22 anos, moravam num pequeno quarto alugado na casa de Bárbara Videla, com duas crianças pequenas, uma de não mais de dois anos e outra de aproximadamente quatro meses - no decorrer do processo ficarse-á sabendo que eram de pais desconhecidos. Depois de terem morado por um bom tempo nessa 
situação, Bárbara confessou ao pároco que achava que os dois irmãos mantinham uma relação incestuosa e, movida pelo conselho do padre, fez a denúncia.

A defesa de ambos os réus baseou-se no argumento de que não havia nenhuma prova clara e de que os réus foram presos baseados apenas na declaração de uma única testemunha - a proprietária da casa, Bárbara Videla -, que mesmo assim declarou que nunca tinha visto nada, mas que suspeitava que os irmãos mantinham relações ilícitas no quarto em que moravam e que por isso "ficou com muito receio até que a sua consciência lhe obrigou um dia a perguntar-lhe à citada Margarita se mantinha algum trato ou amizade ilícita com o irmão e que ela respondeu dizendo-lhe que se soubesse o que se passava com o seu irmão sem dizer mais nada, porque apareceu gente” (f. 9r). A defesa apoiava-se também na declaração de outra testemunha, o marido de Bárbara, Joaquín Videla, que declarou que nunca tinha visto nada raro e que lhe constava que o irmão dormia fora do quarto (f. $17 \mathrm{v})$.

Essas eram as duas únicas testemunhas, e os seus depoimentos não eram concordes. De acordo com a lei, nessas circunstâncias não havia prova plena. Foram ouvidas as confissões dos irmãos, que também não foram concordes. Margarita disse que, por fragilidade, manteve relações ilícitas com seu irmão, mas que foi dois anos antes, quando ele, uma vez, tinha voltado para a sua cidade, Corrientes, quando quase não se conheciam (f. 20r). Francisco disse que deu morada à sua irmã porque ela veio desde Corrientes para fazer uma romaria a Luján e ficou em Buenos Aires, mas negava ter mantido relações com ela (f. 18r). Com relação às crianças, ambos, Margarita e Francisco, declararam que não eram deles, mas de Margarita com dois pais diferentes. Preventivamente, os dois depoentes foram para a reclusão.

O fiscal, aos cinco de agosto de 1791, formalizou a acusação, afirmando que, "embora a prova do delito seja deficiente, há fortes indícios e presunções”, e pediu a pena de presídio para o irmão e a reclusão na residência para Margarita, "para satisfação da vindicta pública ofendida com um delito tão torpe e repugnante” (f. 32r), deixando a decisão ao arbítrio do juiz.

O regedor defensor geral de pobres alegou que a acusação fiscal não tinha em que se apoiar, porque “nem havia testemunha de vista, nem presunções”, mas tão só uma suspeita de Bárbara Videla, que era uma mulher "laxa, rústica por sua natureza e sumamente suspeita”, tendo em conta a declaração contrária do seu marido” (f. 34v). Acrescentou ainda que, se houve delito, estava oculto, e que se havia alguma presunção possível, era a de que eram irmãos, "podendo muito bem ser equivocado o juízo que se fez” (f. 34v). E, para fundamentar ainda mais a sua opinião, fez referência aos comentários de Acevedo, que, referindo-se à lei 7, tít. 2, lib. 8, das Recopiladas, defendia que a suspeita de incesto entre irmãos "requer maior e mais eficaz prova cum naturale foedem nihil in 
talibus permitat suspicari”. Pediu, assim, o regedor defensor geral de pobres, a absolvição e soltura imediata de ambos.

O alcalde ordinário de $2^{\circ}$ voto e juiz de menores, dom Antonio García López, aos seis de janeiro de 1792, sentenciou que fosse dada liberdade a ambos, e que Margarita fosse colocada numa casa de respeito até que pudesse ser enviada aos pais, em Corrientes.

A sentença foi apelada e novamente a defesa voltou a insistir na tese de que não havia provas e nem sequer indícios, mas apenas a suspeita levantada por uma testemunha. A Real Audiência, contudo, revogou a sentença do alcalde ordinário, condenando os irmãos a dois anos.

O segundo processo (ARCHIVO HISTÓRICO DE LA PROVINCIA DE BUENOS AIRES, 1789a) foi iniciado por parte do marido, Juan Antonio Caballero, contra o suposto agressor, Manuel Lezcano, casado, que, sendo pessoa que frequentava regularmente a casa, aproveitou-se dessa situação e da ausência do marido para numa noite invadir a residência e tentar forçar a mulher, Dionísia Michaela de Arriola, batendo nela quando “esta resistiu a suas torpes solicitações” (f. 1r).

O defensor geral de pobres, em nome do réu, alegou "que do suposto delito não há prova alguma, convencimento nem presunção alguma conclusiva” (f. 18r). O seu argumento baseava-se na doutrina que

[...] diz em primeiro lugar que para qualificar os delitos de difícil prova basta neles a prova que em outros é insuficiente, bastando, portanto, indícios, conjecturas e presunções formados de legítimos antecedentes que façam uma conclusão necessária e indubitável com presunção legal, mas é precisamente isso que falta em nosso caso (f. 18r).

E, mais ainda, passava a contestar uma por uma as declarações das testemunhas, mostrando as contradições entre elas, de maneira que entendia que "não qualificam a acusação como verdadeira e muito menos se pode dizer que haja uma presunção certa” (f. 20v).

O alcalde ordinário, Miguel Saenz (que já havia atuado nos dois primeiros casos que vimos de adultério), aos quatro de agosto de 1789, tendo presente que Caballero havia desistido da ação, pretextando indigência, mesmo assim sentenciou a causa de forma singular: ordenou que o agressor Lezcano fosse libertado e o proibiu de ter trato ou comunicação com o casal e até de frequentar as imediações da casa, sob pena de 200 pesos, caso infringisse a ordem, “advertindo-o seriamente para que melhore a sua conduta aos deveres do seu estado, sem dar motivo a nova queixa nem suspeita, procurando em tudo o bom exemplo da sua mulher e família e a aplicação ao trabalho, cujos defeitos são notórios” (f. 26r).

A sentença absolutória foi confirmada pela Real Audiência, mas exigindo que Lezcano pagasse 25 pesos de multa. 
A questão da prova, bem como a distinção entre prova, indício, conjetura e presunção, foi desenvolvida com profundidade, como explica Isabella Rosoni (1995), a partir da reflexão epistemológica do século XVII, elaborando uma profunda "teoria da certeza moral intrinsecamente ligada ao princípio da probabilidade” (ROSONI, 1995, p. 26). Daí, como ela mesma conclui, a importância de verificar um “conjunto de opiniões, todas prováveis e coerentes umas com as outras que, precisamente, levavam a uma certeza provável” (ROSONI, 1995, p. 26). Era aqui, de novo, que se dava o entroncamento entre juristas e moralistas. As provas, bem como os indícios e conjeturas, normalmente davam uma certeza provável e, por isso, o juiz podia, e devia, por meio do seu arbítrio, na hora da apreciação das provas, dar mais valor a umas do que a outras. Por isso que, no primeiro caso, os indícios foram suficientes para condenar, e no segundo, não.

\section{CONSIDERAÇÕES FINAIS}

É relativamente recente o recurso aos processos judiciais por parte dos historiadores, nos quais se percebe um interesse cada vez maior. De fato, esses processos fornecem informações valiosas que estão sendo cada vez mais utilizadas pelos pesquisadores nas áreas da história da família, de gênero, da sexualidade, bem como da história do direito e da justiça.

Procurou-se com o presente trabalho mostrar principalmente duas coisas: em primeiro lugar, perceber o papel e a importância do exercício do arbítrio judicial no contexto do Vice-Reinado do Rio da Prata, tendo-se em conta que o fundamento das relações jurídicas eram a incerteza e a insegurança jurídicas. Contudo, essa incerteza e essa insegurança não eram obstáculos para a administração da justiça; pelo contrário, eram o seu contexto e entorno habituais. Um arbítrio judicial prudente era precisamente a garantia para que, num contexto incerto e inseguro, pudessem ser dadas sentenças justas.

E, em segundo lugar, tendo-se em conta que essa realidade jurídica era casuística, resolvia os assuntos caso a caso, não se podia falar de precedentes, nem pretender unificar ou homogeneizar sentenças e decisões. Pelo contrário, o critério que prevalecia era o de um pluralismo de decisões, de maneira que não apenas juízes diferentes, mas inclusive o mesmo juiz, poderiam, conforme o seu arbítrio e convicção, decidir num caso de uma forma e, em outro, de outra. O justo não era a expressão de um resultado exato e único, mas a proporção conveniente, adequada e ajustada, para mais e para menos, sobre a qual somente o juiz poderia decidir em cada caso e na hora de elaborar e proferir a sentença. 


\section{REFERÊNCIAS}

AGUERO, Alejandro. Castigar y perdonar cuando conviene a la República. La justicia penal de Córdoba de Tucumán, siglos XVII y XVIII. Madrid, 2008.

AGUERO, Alejandro. El testimonio procesal y la administración de la justicia penal en la periferia de la Monarquía Católica, siglos XVII y XVIII. Revista Fontes, São Paulo, Unifesp, 2014.

AZOR, Juan. Institutionum moralium, in quibus universae questiones ad conscientiam recte aut prave factorum pertinentes breviter tractatum [Sobre as instituições morais, nas quais são tratadas todas as questões pertinentes a uma consciência recta ou errada]. 1600.

BARRENECHE, Osvaldo. Esos torpes deseos. Delitos y desviaciones sexuales en Buenos Aires, 1760-1810. Estudios de Historia colonial, n. 13, 1993.

CARRASCO DEL SAZ. Interpretatio ad aliquas leges Recopilationis Regni Castellae. Sevilla, 1620.

CASTILLO DE BOBADILLA, J. Política para corregiroes y señores de vasallos en tiempos de paz y de guerra, Medina del Campo, por Christoval Lasso y Francisco García, 1608.

FUENTES BARRAGÁN, Antonio. Quebrantos de la moral conyugal: amistades ilícitas en el Buenos Aires tardocolonial. Naveg@mérica. Revista electrónica editada por la Asociación Española de Americanistas, n. 15, 2015a.

FUENTES BARRAGÁN, Antonio. Sobre estrategias y pasiones: Etnicidad, honor y matrimonio en la Provincia de Buenos Aires (siglo XVIII). Revista Dos Puntas, Año VII, n. 12, 2015b.

GUARDIOLA Y SAEZ, L. El Corregidor perfecto y juez exactamente dotado de las calidades convenientes y necesarias para el buen Gobierno econômico y político de los pueblos y la más recta administración de justicia en ellos... Madrid, en la Imprenta y Librería de López, 1785.

GUTIÉRREZ AGUILERA, María Selina. Conductas violentas, realidades cotidianas. Familia, sociedad y convivencia en el Buenos Aires del siglo XVIII. Procesos Históricos, Revista de Historia y Ciencias Sociales, 28, julio-diciembre, 2015a, p. 76-91.

GUTIÉRREZ AGUILERA, María Selina. Vidas desdichadas, desenlaces funestos. El deshonor de ser maltratada en el Buenos Aires virreinal. Revista Dos Puntas, Año VII, n. 12, 2015b.

KLUGER, Viviane. El expediente judicial como fuente para la investigación histórico-jurídica. Su utilidad para el estudio de la Historia de la familia colonial. Passagens. Revista Internacional de História Política e Cultura Jurídica. Laboratório Cidade e Poder, v. 1, n. 1, UFF, jan.-jul. 2009.

MALLO, Silvia. Conflictos y armonías. Las fuentes judiciales en el comportamiento y valores familiares. In: CALTON, Dora; GHIRARDI, Mónica; CARBONETTI, Adrián (Coord.). Poblaciones históricas. Fuentes, métodos y líneas de investigación. Serie Investigaciones, n. 9. Brasil: Asociación Latinoamericana de Población (Alap), 2009.

MALLO, Silvia. La mujer rioplatense a finales del siglo XVIII. Ideales y Realidad. Anuario del IEHS, Tandil, 1990. 
MARYKS, Robert Aleksander. Saint Cicero and the Jesuits. The Influence of the Liberal Arts on the Adoption of Moral Probabilism. Hampshire-Rome: Ashgate-Institutum Historicum Societatis Iesu, 2008.

MECCARELLI, Massimo. Arbitrium. Un aspetto sistematico degli ordinamenti giuridici in età di diritto comune. Milão: Giuffrè, 1998.

PADOA-SCHIOPPA, Antonio. Sulla coscienza del giudice nel diritto comune. In: Iuris Vincula, Studi in onore di Mario Talamanca, VI. Napoli: Jovene Editore, 2001.

PINCKAERS, Servais Théodore. Las fuentes de la moral cristiana. Su método, su contenido, su historia. Pamplona: Ediciones Universidad de Navarra, 2000.

ROSONI, Isabella. Quae singula non possunt collecta iuvant. La teoria della prova indiziaria nell'età medievale e moderna. Milano, Giuffrè Editore, 1995.

TARUFFO, M. A Prova. São Paulo: Marcial Pons, 2014.

TAU ANZOÁTEGUI, V. Casuismo y sistema. Indagación histórica sobre el espíritu del Derecho Indiano. Buenos Aires: Instituto de Investigaciones de Historia del Derecho, 1992.

VASSALLO, Jaqueline. Es posible hacer Historia del Derecho desde una perspectiva de género? In: CALTON, Dora; GHIRARDI, Mónica; CARBONETTI, Adrián (Coord.). Poblaciones históricas. Fuentes, métodos y líneas de investigación. Serie Investigaciones, n. 9. Brasil: Asociación Latinoamericana de Población (Alap), 2009.

\section{FONTES PRIMÁRIAS}

ARCHIVO HISTÓRICO DE LA PROVINCIA DE BUENOS AIRES (AHPBA). Sección Criminal Provincial, 5.5.67.5, Causa de oficio de la Real Justicia contra Don Francisco Cavenago y [riscado] sobre amancebamiento, año 1788a.

ARCHIVO HISTÓRICO DE LA PROVINCIA DE BUENOS AIRES (AHPBA). Sección Criminal Provincial, 5.5.80.44, Criminales contra Francisco Balcázar y su hermana Margarita Balcázar, por vivir ilícitamente, año 1790.

ARCHIVO HISTÓRICO DE LA PROVINCIA DE BUENOS AIRES (AHPBA). Sección Criminal Provincial, 5.5.78.2, Autos criminales seguidos por Juan Antonio Cavallero contra Manuel Lazcano, año 1789a.

ARCHIVO HISTÓRICO DE LA PROVINCIA DE BUENOS AIRES (AHPBA). Sección Criminal Provincial, 5.5.68.34, Fructuosa Polibio, esclava de Juan Polibio. Expediente de su destierro dispuesto por el Alcalde de $1^{\circ}$ voto y oposición del Señor Fiscal Protector por el marido Josef Antonio Castro, año 1789b.

ARCHIVO HISTÓRICO DE LA PROVINCIA DE BUENOS AIRES (AHPBA). Sección Criminales, 7.1.88.33, Criminales contra Geronimo Toro por haver trahido del Tucuman una mujer casada, año $1788 \mathrm{~b}$. 
Rafael Ruiz

Professor Associado de História da América na Escola de Filosofia, Letras e Ciências Humanas, do Departamento de História, da Universidade Federal de São Paulo. E-mail: rafarui@hotmail.com 